\title{
ОЦЕНКА ЭФФЕКТИВНОСТИ ПРОВЕДЕНИЯ ГИДРАВЛИЧЕСКОГО РАЗРЫВА ПЛАСТА С ИСПОЛЬЗОВАНИЕМ РЕЗУЛЬТАТОВ СОВРЕМЕННЫХ ГИДРОДИНАМИЧЕСКИХ ИССЛЕДОВАНИЙ СКВАЖИН
}

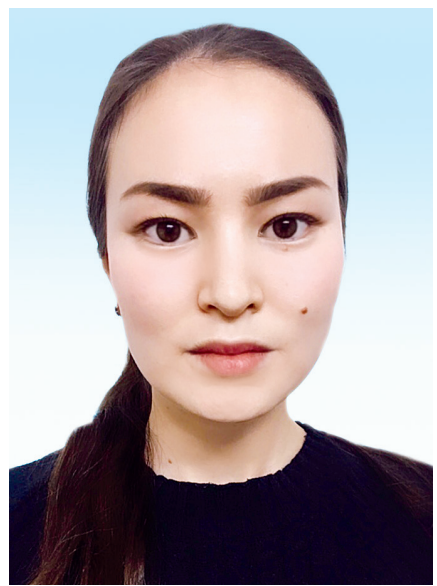

Д. ТЕМИРГАЛИ*, магистрант, https://orcid.org/0000-00021388-7785

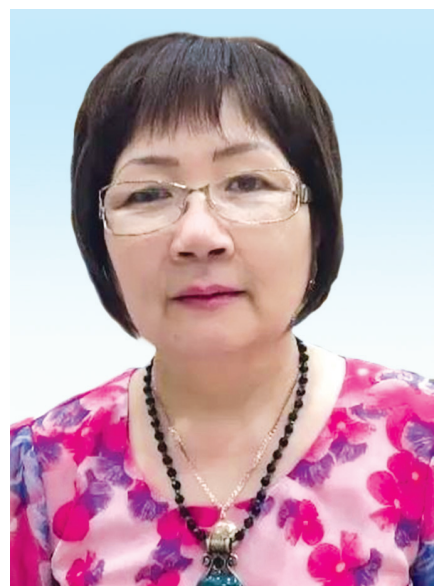

К.С. НУРБЕКОВА, кандидат тех. наук, доцент, https://orcid.org/0000-00022576-5195

АКТЮБИНСКИЙ РЕГИОНАЛЬНЫЙ УНИВЕРСИТЕТ ИМ. ЖУБАНОВА, Республика Казахстан, 030000, г. Актобе, проспект Алии Молдагуловой, 34

Гидравлический разрыв пласта - довольно эфффективный в настоящее время метод интенсифрикации добычи нефти из низкопроницаемых коллекторов, получивший массовое применение везде. Чаще всего гидроразрывы дают положительные результаты, однако эфорективность зависит от геолого-фризических характеристик пластов. Одним из нашболее серьезных фракторов, снижающих успешность проведения, является наличие обширных водонефтяных зон, особенно в залежах, представленных низкопроницаемых коллекторов.

Актуальность исследований обусловлена значительным вкладом объемов нефти, добытых в результате проведения на скважинах гидравлического разрыва пласта (ГРП), в ее суммарной добыче.

Результаты показали, что производительность скважин после ГРП увеличивается, иногда в несколько десятков раз. Это свидетельствует о том, что образованные трещины соединяются с существовавшими ранее, и приток жидкости к скважине происходит из отдаленных, изолированных от скважины до применения ГРП, высокопроизводительных зон.

КЛЮЧЕВЫЕ СЛОВА: гидравлический разрыв пласта, низкопроницаемые коллекторы, оценка эфорективности.

\footnotetext{
* Адрес для переписки. E-mail: dinarat9710@gmail.com
} 


\section{ҰНҒЫМАЛАРДЫ ЗАМАНАУИ ГИДРОДИНАМИКАЛЫҚ ЗЕРТТЕУ НӘТИЖЕЛЕРІН ҚОЛДАНУ АРҚЫЛЫ, ГИДРАВЛИКАЛЫҚ СЫНУ ТИІМДІЛІГІН БАҒАЛАУ}

Д.Т. ТЕМІРҒАЛИ*, Жұбанов атындағы Ақтөбе өңірлік университетінің магистранты, https://orcid. org/0000-0002-1388-7785;

К.С. НҰРБЕКОВА, техника ғылымдарының кандидаты, Жұбанов атындағы Ақтөбе өңірлік университетінің доценті, https://orcid.org/0000-0002-2576-5195

Қ. ЖҰБАНОВ АТЫНДАҒЫ АҚТӨБЕ ӨҢІРЛІК УНИВЕРСИТЕТІ,

Қазақстан Республикасы, 030000, Ақтөбе қаласы, Молдағұлова даңғылы, 34

Гидравликалық сыну қазіргі уақытта өте тиімді, төмен өткізгіш коллекторлардан мұнай өндіруді күшейту әдісі, ол барлық жерде жаппай қолданылады. Көбінесе гидравликалық үзілістер оң нәтиже береді, бірақ тиімділігі қабаттардың геологиялық және фризикалық сипаттамаларына байланысты. Жүргізудің сәттілігін төмендететін маңызды фракторлардың бірі-кең су-мұнай аймақтарының болуы, әсіресе төмен өткізгіш коллекторлар ұсынылған кен орындарында.

Зерттеудің өзектілігі ұңғымаларда гидравликалық сыну (гидравликалық сыну) нәтижесінде өндірілген мұнай көлемінің оның жалпы өндірілуіне айтарлықтай үлес қосуымен байланысты.

Нәтижелерден, гидравликалық сынудан кейін ұңғымалардың өнімділігінің бірнеше есе жоғарлағанын көрдік.

ТҮЙІн СӨзДЕР: гидравликалық сыну, төмен өткізгіш коллекторлар, тиімділікті бағалау.

\section{EVALUATION OF THE EFFECTIVENESS OF HYDRAULIC FRACTURING USING THE RESULTS OF MODERN HYDRODYNAMIC STUDY OF WELLS}

D.T. TEMIRGALI*, Master's degree student of Zhubanov Aktobe Regional University, https://orcid. org/0000-0002-1388-7785

K.S. NURBEKOVA, candidate of technical sciences, associate professor of Zhubanov Aktobe Regional University, https://orcid.org/0000-0002-2576-5195

K. ZHUBANOV AKTOBE REGIONAL UNIVERSITY,

34, A. Moldagulova Avenue, 030000, Aktobe, Republic of Kazakhstan

Hydraulic fracturing is currently a very effective method of strengthening oil production from low-permeable reservoirs, which is widely used everywhere. Most often, hydraulic fracturings have a positive effect, but the effectiveness depends on the geological and physical characteristics of the layers. One of the most important factors that reduce the success of driving is the presence of wide water-oil zones, especially in fields where low-permeable reservoirs are represented. In this case, the question arises: to extend the operation of wells with low oil yields or to increase the volume of water.

The results showed that the productivity of wells after hydraulic fracturing increases, sometimes by several tens of times. This indicates that the formed cracks are connected to the existing ones, and the flow of liquid to the well occurs from remote, isolated from the well before the use of hydraulic fracturing, high-performance zones.

KEY WORDS: hydraulic fracturing, low-permeability reservoirs, efficiency assessment.

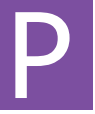

езультат применения любой технологии, направленной на добычу углеводородов, может зависеть от множества факторов как геолого-физических и физико-химических, так и геотехнологических. Как правило, чем сложнее процесс или технология добычи нефти, тем больше качественных и количественных 
параметров и свойств должно учитываться при оценке его эффективности. Одной из наиболее сложных и дорогостоящих технологий, нацеленных на увеличение степени нефтеизвлечения, является гидроразрыв пласта (ГРП). После проведения скважино-операции ГРП «на выходе» можно получить более тысячи параметров и около десяти графиков, которые можно выделить в несколько групп: параметры контроля качества ГРП, параметры сводных данных, финансовые параметры, результаты анализа мини-ГРП, результаты анализа основного ГРП. Все параметры прямо или косвенно могут использоваться для оценки эффективности ГРП. В последнее десятилетие отмечается увеличение объемов применения ГРП. Гидравлический разрыв пласта проводится практически на всех месторождениях. Для решения задач прогнозирования гидравлического разрыва пласта достижения достаточно высоких технико-экономических показателей эффективности мероприятий необходима объективная оценка его эффективности.

Гидродинамические исследования скважин (ГДИС) - совокупность различных мероприятий, направленных на измерение определенных параметров (давление, температура, уровень жидкости, дебит и др.) и отбор проб пластовых флюидов (нефти, воды, газа и газоконденсата) в работающих или остановленных скважинах и их регистрацию во времени.

Среди всех известных методов ГДИС, используемых для определения фильтрационных параметров пласта, геометрии и проводимости трещины после ГРП, наиболее предпочтительным является исследование с регистрацией кривой восстановления давления (КВД) на забое скважины. В скважинах, эксплуатируемых с применением установок электроцентробежных насосов (УЭЦН), можно проводить исследование КВД с высокой точностью с предварительным спуском автономного глубинного манометра УЭЦН. Исследование включает фиксирование участка изменения забойного давления - кривую падения давления (КПД) после ввода насоса в работу и замеры дебита скважины с последующей регистрацией участка КВД после ее остановки. В зависимости от проницаемости пласта исследование занимает примерно 1,5 - 2 мес. с последующим извлечением оборудования. Наиболее корректные данные о параметрах пласта и трещины можно получить по КВД. Данные, полученные по КПД, имеют погрешность, так как при запуске в работу скважины сначала происходит приток к ней жидкости глушения и только затем поступает пластовый флюид. На этапе принятия решения о выборе скважин кандидатов для проведения ГРП данные о характеристиках пласта могут получены из исследования кривой восстановления уровня (КВУ). Результаты исследований до и после проведения ГРП позволят наиболее точно оценить эффективность выполненного в скважине мероприятия [1]. Оценка параметров трещины ГРП с помощью снятия КВД основывается на выявлении и анализе режимов притока пластовой жидкости в скважину за счет перераспределения давления в пласте с трещиной ГРП после ее закрытия [2].

Метод кривой восстановления давления (КВД) применяется для скважин, фонтанирующих с высокими и устойчивыми дебитами.

Исследование методом КВД заключается в регистрации давления в остановленной скважине (отбор жидкости прекращён), которая была закрыта путём гермети- 


\section{РАБОТЫ МОЛОДЫХ УЧЕНЫХ}

зации устья после кратковременной работы с известным дебитом (тест Хорнера) или после установившегося отбора (метод касательной).

Для определения параметров удалённой от скважины зоны пласта длительность регистрации КВД должна быть достаточной для исключения влияния «после притока» (продолжающегося притока жидкости в ствол скважины), после чего увеличение давления происходит только за счёт сжатия жидкости в пласте и её фильтрации из удалённой в ближнюю зону пласта (конечный участок КВД).

При обработке реальных кривых восстановления давления (КВД) первое, что необходимо учитывать - это наличие притока из пласта после остановки скважины, который, как правило, неизвестен. Поэтому информацию о дебите пытаются получить из динамики давления. В литературе известен ряд таких методов. Наверное, самый простой из них - метод поправочного коэффициента [1]. Метод предполагает дифференцирование (численное) кривой изменения давления во времени. Для большинства реальных ситуаций - это только вид кривой изменения дебита, а для расчета конкретных значений необходимо получить поправочный коэффициент путем экстраполяции на значение времени, равное нулю. При попытке внести некоторые улучшения, появился метод, который, видимо, можно называть модификацией метода поправочного коэффициента или методом максимальной линеаризации. Для тестирования метода использовались модельные решения восстановления давления в пласте с учетом притока. Использование модельных примеров имеет свои преимущества, так как позволяет исключить все другие факторы и вычленить более ярко влияние изучаемых. [2-3]

Модель содержит обычно используемые допущения об однородности пласта, плоской поверхности его границ и т.п. Приток из пласта задавался экспоненциальной функцией, достаточно близкой к реальным кривым дебита притока после остановки скважины. Математическая формулировка задачи в рамках классического упругого режима фильтрации выглядит следующим образом:

$$
\begin{gathered}
\frac{\partial p}{\partial t}=\frac{k}{r} \frac{\partial}{\partial r}\left(r \frac{\partial p}{\partial t}\right), r_{c}<r<R_{k} \\
t=0, p=p_{0} \\
r=r_{c}, 0<t<t_{0}\left(r \frac{\partial p}{\partial t}\right)=\frac{\mu q}{2 \pi k h} \\
r=R_{k},\left(r \frac{\partial p}{\partial t}\right)=0
\end{gathered}
$$

где $t$ - время, $r$ - радиальная координата, $t_{0}$ - момент остановки скважины, $\kappa-$ коэффициент пьезопроводности, $p$ - давление. Используемые параметры: радиус скважины $r_{c}-10$ см, радиус контура питания $R_{k}-3000$ м, проницаемость $k-0.5$ мкм 2 , вязкость нефти $\mu-3$ спз, коэффициент упругоемкости $\beta=4 * 10-51 /$ ат, начальное пластовое давление $p_{0}=100$ ат, дебит $q_{0}-10 \mathrm{~cm}^{3} / \mathrm{c}$, дебит притока $q_{0}^{*} \exp (-0.0003 \mathrm{t})$, скважина 300 суток работала в стационарном режиме, была остановлена и 10 - суток регистрировалось восстанавливаемое давление. Результаты были обработаны несколькими способами: без учета притока, с учетом того притока, который заложен 


\section{РАБОТЫ МОЛОДЫХ УЧЕНЫХ}

в самой задаче (т.е. наиболее точный для данного примера), методом поправочного коэффициента. [4]

Графики представлены на рисунке 1. Обращает на себя внимание прямая, которая свидетельствует, что при учете точного дебита преобразованная зависимость является идеально линейной с первых же точек КВД. Указанное свойство и предлагается положить в основу обработки.

В данном примере метод поправочного коэффициента проявил себя не с лучшей стороны. Рассчитанный указанным способом дебит уже на времени 600 с имеет отклонение $21 \%$ от истинного и далее это отклонение быстро растет и доходит до $100 \%$. По сути дела реально используется для определения гидродинамических параметров тот же диапазон точек, что и для метода без учета притока. С целью улучшения точности определения притока по кривой давления было предложено следующее.

Во-первых, сгладить кривую изменения давления во времени, аппроксимировав полиномом, можно при этом использовать логарифмический характер кривой

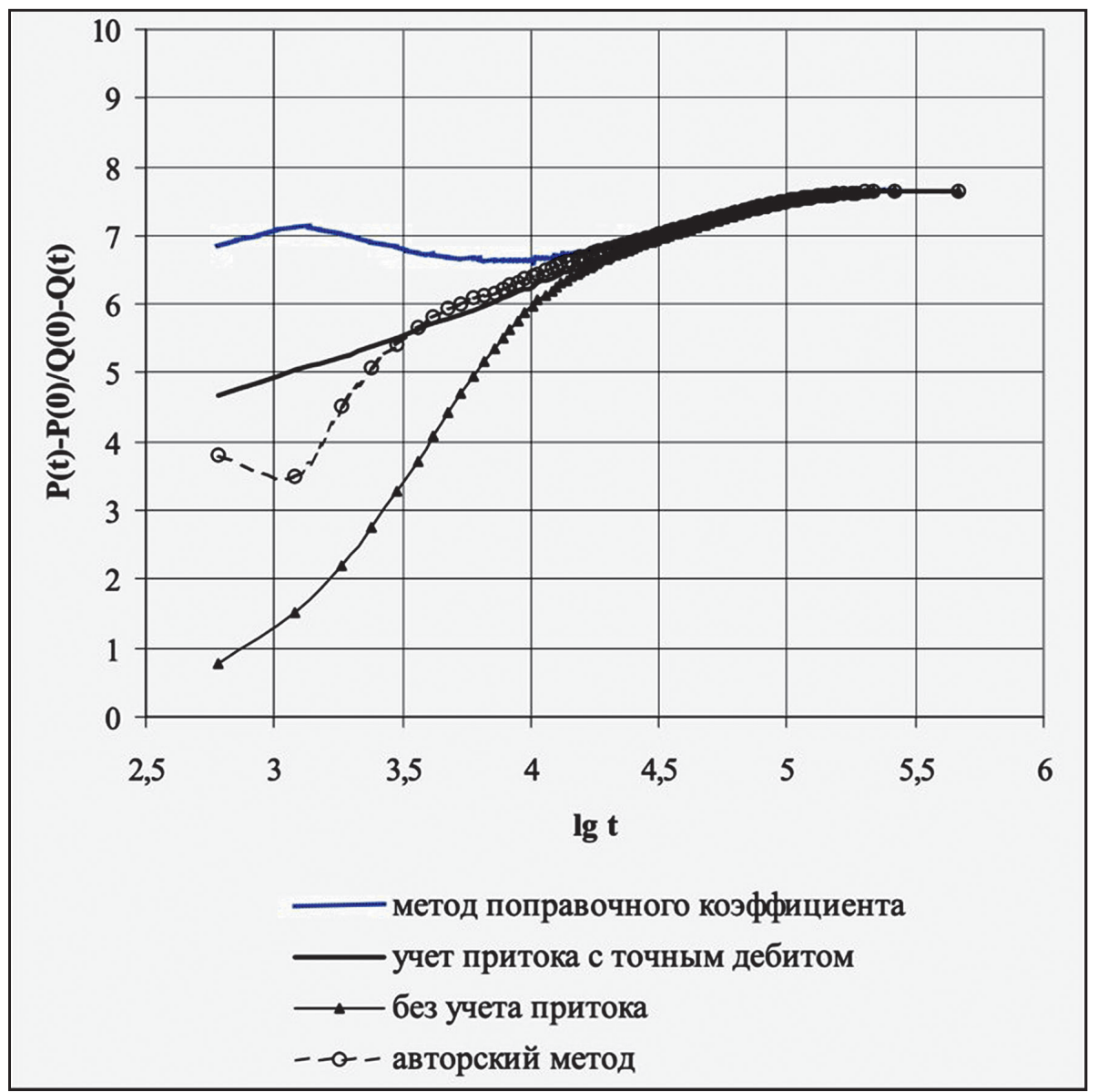

Рисунок 1 - Кривая восстановления давления, модельный пример 


\section{РАБОТЫ МОЛОДЫХ УЧЕНЫХ}

давления после остановки скважины и аппроксимировать кривую давления в координатах (P, $\lg$ t). Особое внимание необходимо уделить участку, расположенному до линейной части кривой. [5] Главная задача состоит в линеаризации более ранних точек. Однако вряд ли необходимо тратить время на линеаризацию самых первых точек где-то до 10 мин. Это может оказаться даже невозможно.

Во-вторых, продифференцировать полученный полином аналитически - полученная кривая тоже будет гладкой. Во-первых, сгладить кривую изменения давления во времени, аппроксимировав полиномом, можно при этом использовать логарифмический характер кривой давления после остановки скважины и аппроксимировать кривую давления в координатах (P,lg t). Особое внимание необходимо уделить участку, расположенному до линейной части кривой. Главная задача состоит в линеаризации более ранних точек. Однако вряд ли необходимо тратить время на линеаризацию самых первых точек где-то до 10 мин. Это может оказаться даже невозможно. Во-вторых, продифференцировать полученный полином аналитически, полученная кривая тоже будет гладкой.

В-третьих, остается только подобрать поправочный коэффициент для преобразования последней кривой в реальный дебит. В данном случае предлагается подбирать его исходя из наилучшей линеаризации КВД, построенной с учетом этого притока. Поскольку точный дебит, участвующий в преобразовании, дает графически прямую линию, как это наглядно видно из приведенного графика [4].

Для примера обработки реальной КВД использованы данные, опубликованные в упомянутой работе . Все виды КВД (зарегистрированная и обработанная двумя методами) приведены на рисунке 1. Из графика видно, что предлагаемый метод по сравнению с методом поправочного коэффициента обеспечивает меньшую осцилляцию и большую уверенность в значении углового коэффициента, естественно возрастает величина достоверности аппроксимации. При этом интервал линейности кривой увеличивается в сторону меньших времен.

Очевидно, что целью гидроразрыва является усиление текущего взрыва и повышение коэффициента добычи нефти при освоении низкопроницаемых залежей и, в конечном счете, добычи нефти по месторождению.

Факторы, обеспечивающие успешность плановых операций гидроразрыва, следующие:

- наличие необходимой ресурсной базы;

- наличие большого запаса перспективных скважин для реализации

гидроразрывная корка;

- своевременное использование высококачественной зарубежной продукции;

увеличение производства оборудования, технологий и материалов, обеспечивающих стабильный доход. 


\section{РАБОТЫ МОЛОДЫХ УЧЕНЫХ}

\section{ЛИТЕРАТУРА}

1 Сеитов Н., Жаркынбеков Т.Н. Геотектоника и геодинамика. - Алматы: КазНТУ, 2013 173 c. [Seitov N., Zharkinbekov T.N.Geotektonica i geodinamika. - Almaty: KazNTU, $2013 .-173$ p. ]

2 Чернова О. С. Основы геологии нефти и газа: учебное пособие. - Томск, 2008. - 372 с. [Chernova O.S. Osnovy geologii nefti i gaza: uchebnoe posobie. - Tomsk, 2008. - 372 s.]

3 Муравьев И.М. и др. Разработка и эксплуатация нефтяных и газовых месторождений. - М.: Недра, 1970. [Murav'ev I. M. et al.. Razrabotka i ekspluataciya neftyanyh i gazovyh mestorozhdenii. - Moskva: Nedra, 1970.]

4 Александров С.И., Гогоненков Г.Н., Пасынков А.Г. Пассивный сейсмический мониторинг для контроля геометрических параметров гидроразрыва пласта // Нефтяное хозяйство. - 2007. - № 3. - С. 51-53. [Alexandrov S.I., Gogonenkov G. N., PasynkovA. G. Passivnyi seismicheskii monitoring dlya kontrolya geometricheskih parametrov gidrorazryva plasta Neftyanoe hozyajstvo. - 2007. - № 3. - S. 51-53.]

5 Валеев А.С., Дулкарнаев М.Р., Котенев Ю.А., Султанов Ш.Х., Бриллиант Л.С. Причины увеличения обводненности в скважинах после проведения гидравлического разрыва в неоднородных пластах // Нефртяное хозяйство. - 2019. - Т. 329. - №6. - С. 140-147 [Valeev A. S., Dulkarnaev M. R., Kotenev Yu. A., Sultanov Sh. Kh., Brilliant L. S. Prichiny uvelichenia obvodnennosti v skvazhinah posle provedeniya gidravlicheskogo razryva v neodnorodnyh plastah // Neftyanoe hozyajstvo. - 2019. - T. 329. - №6. - S. 140-147]

7 Воеводкин В.Л., Алероев А.А., Балдина Т.Р., Распопов А.В., Казанцев А.С., Кондратьев С.А. Развитие технологий гидравлического разрыва пласта на месторождениях Пермского края// Нефтяное хозяйство. - 2018. - № 5. - С. 108-113. [Voevodkin V.L., Aleroyev A. A., Baldina T. R., Raspopov A.V., Kazantsev A. S., Kondratyev S. A. Razvitie technologii gidravlicheskogo razryva plasta na mestrozhdeniyah Permskogo kraya // Neftyanoe hozyajstvo. - 2018. - № 5. - S. 108-113. 